\title{
培养学生科学思维核心素养对当前物理课堂环节有效性实践 探究
}

\author{
马友 \\ 天津市静海区第一中学 \\ DOI:10.32629/er.v2i2.1679
}

[摘 要] 创设问题情境是教师引导学生提出问题,培养和提高学生科学思维的重要步骤。它也是建立高效物理课堂的重要教 学环节。教师灵活的应用问题情景创设可以提高学生学习的兴趣,达到培养能力的目的,从而提升物理学科的核心素养。本文 重点围绕高中物理课中如何实施有效的问题情境创设,及创设过程中如何关注“科学思维”这一核心素养进行阐述。

[关键词]问题情境创设; 科学思维; 有效性

物理学科的核心素养包括: 物理观念、科学思维、实验 探究及科学态度与责任。其中的 “科学思维” 素养是指: 从 物理学视角对客观事物的本质属性、内在规律及相互关系的 认识方式; 是基于经验事实建构物理模型的抽象概括过程; 是分析综合、推理论证等方法在科学领域的具体运用; 是基 于事实证据和科学推理对不同观点和结论提出质疑和批判, 进行检验和修正, 进而提出创造性见解的能力与品质。“科学 思维” 主要包括模型建构、科学推理、科学论证、质疑创新 等要素。

科学思维素养对高中生的能力要求为: 通过学习, 学生 应具有建构理想模型的意识和能力; 能运用科学思维方法, 从定性和定量两个方面进行科学推理、找出规律、形成结论; 具有使用科学证据的意识和评估科学证据的能力, 能运用证 据对研究的问题进行描述、解释和预测; 具有批判性思维的 意识, 能基于证据大胆质疑, 从不同角度思考问题, 追求科技 创新。

基于核心素养对高中学生能力的要求, 我们要努力提升 自己的课堂教学, 让核心素养融入到教学的各个环节中去, 实施潜移默化的教育。而让物理课堂更具有效性, 我们就要 从上课的而第一环节一一创设问题情境入手。

“问题情境” 就教师在教学目标指引下, 能够通过分析、 理解、概括、归纳等方法达成目标而创设的学习情境。它应 针对教学目标、启发学生思维、引导学生发现问题, 还应具 有一定的趣味性来吸引学生, 增强互动性让学生参与其中。 建构主义理论明确指出: 学生的学习过程不是一个简单的知 识接受过程, 而是一个基于学生自身原有生活经验与知识基 础主动建构的过程。因此, 教师始终要关注学生的学习兴趣 和学习习惯, 在教学过程中还要注重学习方法的教育和培养, 来不断地提升学生的物理学习能力, 提高物理学科的核心素 养, 使课堂教学更有效。

1 在生活和自然中的物理现象背景下创设问题情境,并 激发学习兴趣

“从生活走向物理, 从物理走向社会” 是当今物理教学
的基本理念之一。学生身边熟悉的生活现象以及自然界中常 见的天文、气象、地质运动等现象中都蕴藏着丰富的物理学 知识, 这些都是学生学习物理的兴趣来源。教师要从这些现 象中精心挑选适合教学内容的、能够激发学生的好奇心从而 产生学习兴趣进而引发学生思维冲突的素材, 进行问题情境 的创设, 让学生思维快速的进入课堂, 带着对新鲜事物的好 奇和新知识的求知欲进行学习。

例如, 在进行 “光的颜色 色散” 部分的教学时, 教师经 常以学生常见的彩虹为例引入新课。学生对彩虹虽然熟悉, 但通常学生只关注到了一次彩虹现象中的部分现象一一虹, 而忽略了另一部分一一霓。在课件中展示完整的彩虹现象一 一既有虹又有霓, 从而打破既有认知可以让学生对新科有期 待。为了引入薄膜干涉, 我将泡泡机带进课堂, 真实的在学生 面前展示泡泡上的彩色条纹唤起学生的记忆进而激发学生 探究原因的兴趣。从我们周围的常见现象出发, 学生能快速 的构建模型, 从而提高课堂教学的教学效果。

2 在科技前沿环境的背景下创设问题情境,培养学生的 探究能力

高中物理课的教学应培养学生正确的学习和思维方式, 提升学生的学习能力, 鼓励学生发现和解决问题。创设问题 情境既要提高学生关注社会的意识, 还要努力调动学生学习 的主动性和积极性。

例如, 在进行 “带电粒子在匀强磁场中的运动” 的教学 时, 我们可以借用当今科学界的一个争论一一中国该不该建 造世界上最大的粒子对撞机来展开。我们不去关注要不要建 设, 而是关注它的工作原理一一磁场对粒子的约束, 使学生 意识到先进科技中也有我们要掌握的物理知识。学生产生质 疑后在用洛伦兹力演示仪进行模拟, 学生的学习兴趣就会增 强, 学习起来动力就会更足。新鲜的科技前沿与学生学习的 知识相结合, 不仅可以快速的吸引学生, 同时能增强学生的 信心, 进而提高学习物理的热情。

3 在创新实验的背景下创设问题情境,培养学生实践能 力,提高课堂效率 
物理学是一门以实验为基础的科学, 实验既可以直观、 形象地提供感官体验, 又可以激发学生的好奇心和求知欲。 教学时, 如能利用学生身边的材料进行试验, 或者将学生身 边的物理现象用简单的模型呈现在他们眼前, 学生便会引起 认知冲突, 同时在观察与思考中发现问题、提出问题, 进而去 解决问题。

例如, 在讲 “生活中的圆周运动”一节时, 为了突破火车 转弯时的圆周运动是在水平面内完成的这一难点时, 可以引 导学生利用几个规格相同的三角板和一段电线搭建一条 “铁 轨”, 然后用橡皮代替火车让其沿轨道运动, 从而确定水平的 轨道平面。在突破离心现象时, 可以用矿泉水瓶和筷子做一 个 “甩干桶模型”。将矿泉水瓶下半部分减下来扎好孔, 用筷 子当轴, 沾湿棉花, 教师就可以提问 “如何能让棉花尽快变 干? ” 学生很快就能由模型联想到洗衣机, 进而理解离心现 象, 教师在进一步的解释现象的成因, 学生的理解记忆便更 加深刻了。

4 在物理学史的背景下创设问题情境,培养学生的创造 性思维

物理学科容易激发学生的创新思维, 物理学史中物理学 家们在发现物理规律的过程又是艰辛的。让学生了解这些过 程, 了解物理学家在思想认识上所经历的失败及得到的启迪, 对于学生创造新思维同样有启迪作用。

例如, “伽利略对落体运动的研究” 的教学, 我们创设情 境就可以在教材已有物理学史的基础上进一步的丰富相关 史实。这一概念中学生有 “比萨斜塔实验” 的印象, 但在教 学之初, 如果给学生介绍伽利略《两种新科学的对话》中关 于落体运动的分析一一将中的物体绑在轻的物体上与原来 重的物体相比, 谁下落的快一一来引起学生思维的碰撞, 进 而介绍伽利略科学研究的思维, 使学生对科学研究方法印象 更加深刻。再比如, 在 “划时代的发现” 这一课的教学时, 要让学生体会到科学结论得来的不易, 我便在问题创设时加 上了 “从奥斯特发现电流的磁效应, 直到法拉第发现电磁感 应定律这十年间伽利略的坚持, 以及中途亨利的半途而废”, 让学生体会坚持在物理学发展过程中的重要意义。

不仅外国科学家的例子可以引用, 我国同样有着诸多的
科技先人。发掘先人的科学发现, 利用我国历史名人的科研 实例创设问题情境, 既能兼顾知识的教授, 又能提升学生在 科学技术方面的民族自豪感, 激励学生努力学习。

例如, 在 “万有引力定律” 部分内容的教学时, 教师的情 境创设不仅要介绍牛顿的发现, 还应该加入张衡对天文学的 贡献; 在 “电荷守恒定律” 和 “磁场” 的教学时可以加入王 充及《论衡》的介绍; 在《磁场》内容的教学时还应拓展沈 括及《梦溪笔谈》的介绍等等。

通过以上的实践, 我认为问题情境创设要努力揭示事物 的矛盾、引起学生知识的冲突, 引起学生的质疑。激发学生 的思维, 激发学生学习的内驱力, 使学生有积极探索和解决 问题的欲望。我们的问题情境创设还要引导学生参与到物理 学习活动之中, 实现掌握知识、训练思维能力、培养学科素 养的目的。有效的问题情境创设, 既要明确学生现有的知识 能力, 又要利用好学生的 “最近发展区”; 既要构建起完整的 知识结构, 又要形成科学的学习方法。高效的问题情境创设 更要有利于学习能力的提高, 从而实现从 “要我学” 到 “我 要学” 的转变。

高效的物理课堂, 不仅要让学生学会知识, 还要让学生 在学习中形成学科素养。为实现这一目标, 教师首先就要为 学生创设一个良好的学习环境和氛围, 让学生想学习、要学 习。形式多样的情境创设既是枯燥课堂的调味剂, 又是学生 思维的发动机。富有挑战性和趣味性的情境创设, 定能提升 我们物理课堂, 又能点燃学生智慧的火花。

\section{[参考文献]}

[1]《普通高中物理棵程标准(2017 年版)》[M].人民教育 出版社.2017:23-28.

[2]王建华.试论物理学科的科学素养 [J]. 《读与 写》,2018(10):191.

[3]王高.物理核心素养培养浅探 [J]. 《物理教 师》,2016(12):15-19.

[4]陈一鸣.基于物理素养导向的高考物理试题探析及教 学建议[J].《广东教育(综合版)》,2017(11):48-49.

[5]张春丽, 陈颖.关于高中物理实施 “科学论证教学”的 调研与思考[J].《物理教师》,2018(5):2-5. 